\title{
Epidemiological and Clinical Features of Diaper Dermatitis in Infants at the Yaounde Gynaeco-Obstetric and Pediatric Hospital, Cameroon
}

\author{
Andreas Chiabi ${ }^{1,2}$ Jenny Christelle Ngamgo Kamdem ${ }^{3}$ Anita Grâce Nkoro ${ }^{1}$ Hippolyte Siyou ${ }^{1}$ \\ Evelyn Mah ${ }^{1,2}$ Félicitée Dongmo Nguefack ${ }^{1,2}$ Seraphin Nguefack ${ }^{1,2}$ Fru Angwafo III $^{1,2}$ \\ ${ }^{1}$ Yaounde Gynaeco-Obstetric and Pediatric Hospital, Yaounde, \\ Cameroon \\ 2 Department of Pediatrics, Faculty of Medicine and Biomedical \\ Sciences, University of Yaounde I, Yaounde, Cameroon

\begin{abstract}
Address for correspondence Andreas Chiabi, MD, Yaounde GynaecoObstetric and Pediatric Hospital, Cameroon, Faculty of Medicine and Biomedical Sciences, University of Yaounde I, P.O. Box 4362, Yaounde, Cameroon (e-mail: andy_chiabi@yahoo.co.uk).
\end{abstract}

3 Université de Montagnes, Bangangté, Cameroun

J Child Sci 2018;8:e46-e49.

\begin{abstract}
Keywords

- diaper rash

- infant

- epidemiology

- clinical features

Diaper dermatitis is defined as an inflammatory reaction localized on the skin that is usually covered by the diaper (genitals, buttocks, and anus). The aim of this study was to determine the prevalence of diaper dermatitis and to describe the clinical presentation and practices related to hygiene in infants with diaper rash at the Yaounde Gynaeco-Obstetric and Pediatric hospital. It was a descriptive cross-sectional study undertaken in 1,004 mother-children pairs. Data were collected using structured questionnaires during face-to-face interviews with the parents. The prevalence of diaper dermatitis was $18.4 \%$, and infants were aged 7 days to 24 months with a mean age of 5.91 months. The most represented age group was 0 to 6 months (67.6\%). Infants living in urban areas (59.5\%), of unemployed mothers or guardians (30.3\%), and those of mothers living as a couple (75.1\%) were most represented in our study sample. The majority of infants used both disposable and reusable diapers (48.6\%). In addition, 72.7\% mothers used palm kernel oil, and $27.3 \%$ rubbed other ointments before changing the baby's diapers. The most frequent clinical form was the chaffing form (48.1\%). Healthcare personnel should inform, educate, and communicate with mothers on body hygiene of their babies to avoid this disorder, which can cause severe discomfort and sometimes lead to complications.
\end{abstract}

\section{Introduction}

The terms "diaper rash" or "nappy rash," or "diaper dermatitis" are used to designate any skin irritation in infants appearing on the area covered by the diaper. ${ }^{1,2}$ It is one of the most common disorders in infants and newborns, accounting for 10 to $20 \%$ of all skin diseases. ${ }^{3}$ The precise and specific etiology of diaper dermatitis has not yet been determined. ${ }^{4}$ However, irritation

received

April 15, 2018

accepted after revision

July 25, 2018
DOI https://doi.org/

10.1055/s-0038-1669424. ISSN 2474-5871. with skin maceration due to prolonged or frequent contact with soiled diapers is often indicated. ${ }^{5}$

Knowing the epidemiological and clinical features of this disorder is important for effective prevention. This study was thus undertaken at the Yaounde Gynaeco-Obstetric and Pediatric hospital, which is a mother-child hospital, to assess the epidemiological and clinical aspects of this disorder in an urban Cameroonian context.
Copyright $\odot 2018$ Georg Thieme Verlag License terms KG Stuttgart · New York
(®) $\Theta \circledast$ 


\section{Materials and Methods}

This is a descriptive cross-sectional study, at the vaccination and outpatient consultation units of the Yaounde GynaecoObstetrics and Pediatric hospital. The study was conducted from February 1, 2017, to June 30, 2017 (5 months).

We consecutively enrolled all infants aged less than 24 months, brought for vaccination or pediatric consultation, over the study period. The exclusion criteria were: children with a life-threatening emergency requiring immediate hospitalization and children whose parents refused to participate in the study.

The variables noted were: sex and age of the infant, age of the mother, frequency of change of the diapers, frequency of baths, sociodemographic data of the mothers and infants, hygiene practices performed for the infant, and clinical features.

All infants enrolled at the vaccination and/or outpatient consultations were undressed and examined. At the end of the physical examination, the elementary lesions observed, as well as their location, permitted us to describe the different types of diaper dermatitis if found. The dermatitis was noted as "W" type diaper dermatitis or chaffing dermatitis, or frictional dermatitis, if erythema was found on the inner part of the thighs and extends in girls to the labia majora and in boys to the inguinoscrotal region, not affecting the inguinal folds. It was noted as "Y" type dermatitis or Candida albicans dermatitis when the erythema was present on the inguinal and intergluteal folds, and irritant contact dermatitis when the erythema affected the intergluteal folds, the gluteal, perianal, and the pubic regions.

Data were entered and analyzed with the software Epi info version 3.5.4.

Authorization and ethical clearance to perform the study were obtained from the administration of the hospital. Informed consent to participate in the study was obtained from the parents before enrollment.

\section{Results}

During the study period, we received 1,155 infants aged from 7 weeks to 24 months. We examined 1,004 infants, of which 185 had a diaper rash, giving a prevalence of $18.4 \%$.

The sociodemographic profile of infants is summarized in -Table 1.

Table 1 Sociodemographic profile of the infants (total number of patients: 185)

\begin{tabular}{|c|c|c|}
\hline & Number & Percentages (\%) \\
\hline \multicolumn{3}{|l|}{ Age group } \\
\hline $0-6$ months & 125 & 67.6 \\
\hline $6-12$ months & 48 & 25.9 \\
\hline $12-18$ months & 12 & 6.5 \\
\hline \multicolumn{3}{|l|}{ Sex } \\
\hline Male & 91 & 49.2 \\
\hline Female & 94 & 50.8 \\
\hline
\end{tabular}

The most represented age group was 0 to 6 months. The mean age was 5.91 months with extremes from 7 weeks to 24 months. Out of 185 infants with diaper rash, $50.8 \%$ were female, and $49.2 \%$ were male giving a sex ratio of 0.97 . The sociodemographic profile of parents is summarized in - Table 2.

In our study population, 59.5\% resided in urban areas (-Table 3). The most represented maternal age group was between 20 and 30 years, i.e., 51.9\%. Infants whose parents lived together were represented in $75.1 \%$ of the cohort. Regarding the practices of hygiene care, $48.6 \%$ used both types of diaper (reusable and disposable). Infants having a frequency of diaper change less than 6 times a day were the most affected by diaper rash $(76.8 \%)$, and $90.3 \%$ were not cleaned after passing urine. The most frequently used topical treatment was palm kernel oil (72.7\%). Wipes were the most used cleaning agents for the skin at $75.7 \%$. The most frequent clinical form of diaper dermatitis was the "W" or chaffing or frictional form in 89 (48.10\%) cases. The irritant contact dermatitis and the "Y" or Candida dermatitis occurred in 52 and 44 cases, respectively, i.e., $28.1 \%$ and $23.8 \%$, respectively.

\section{Discussion}

In our study, $18.4 \%$ of infants had diaper rash, which is lower than that found by Li et al in 2012 in China, which was $43.8 \%{ }^{6}$ Indeed, the study by $\mathrm{Li}$ et al focused on the study of risk factors in infants from 1 to 24 months in China and was conducted in five different hospitals, while our study was conducted in a single hospital.

The age of the infants ranged from 1 week to 24 months with a mean age of 5.91 months, and the most represented age group was 0 to 6 months. Our results are similar to those of Wanjiku et al in 2016 in Kenya. ${ }^{7}$ Infants in the 6 to 12 months age group were predominant in the study of Biranjia and Pandamikum in 2015 in the Mauritius island, ${ }^{8}$ whose study focused on diaper rash in babies less than 36 months of age. In the study in Mauritius, infants who

Table 2 Sociodemographic profile of the mothers or guardians (total number of patients: 185)

\begin{tabular}{|l|l|l|}
\hline & Number & Percentages (\%) \\
\hline Age group of the mother or guardian \\
\hline$<20$ years & 8 & 4.3 \\
\hline $20-30$ years & 96 & 51.9 \\
\hline $30-40$ years & 77 & 41.6 \\
\hline $40-50$ years & 4 & 2.2 \\
\hline Area of residence \\
\hline Urban & 110 & 59.5 \\
\hline Rural & 75 & 40.5 \\
\hline Marital status & 139 & 75.1 \\
\hline Living as a couple & 139 & 24.9 \\
\hline Living alone & 46 &
\end{tabular}


Table 3 Hygiene practices (total number of patients: 185)

\begin{tabular}{|c|c|c|}
\hline & Number & Percentages (\%) \\
\hline \multicolumn{3}{|l|}{ Diaper type } \\
\hline Disposable & 72 & 38.9 \\
\hline Reusable & 23 & 12.4 \\
\hline Both & 90 & 48.6 \\
\hline \multicolumn{3}{|c|}{ Frequency of change } \\
\hline$<6$ times a day & 142 & 76.8 \\
\hline$\geq 6$ times a day & 43 & 23.2 \\
\hline \multicolumn{3}{|c|}{ Do you clean the child when he urinates? } \\
\hline Yes & 18 & 9.7 \\
\hline No & 167 & 90.3 \\
\hline \multicolumn{3}{|c|}{ Cleaning agents for the skin } \\
\hline Wipes & 140 & 75.7 \\
\hline Wet diapers & 15 & 8.1 \\
\hline Toilet paper & 2 & 1.1 \\
\hline \multicolumn{3}{|c|}{ Topical treatments } \\
\hline Palm kernel oil & 133 & 72.7 \\
\hline Ointment $^{\mathrm{a}}$ & 50 & 27.3 \\
\hline Cream $^{b}$ & 13 & 7.1 \\
\hline Powder ${ }^{c}$ & 13 & 7.1 \\
\hline Olive oil & 7 & 3.8 \\
\hline Milk & 3 & 1.6 \\
\hline Perfume & 3 & 1.6 \\
\hline
\end{tabular}

${ }^{a}$ Antibiotics, anti-fungal agents, and anti-inflammatory.

${ }^{\text {b} T r a d i t i o n a l ~ a n d ~ p h a r m a c e u t i c a l . ~}$

${ }^{\mathrm{C}}$ Pharmaceutical and baby powders.

had had at least one previous episode of diaper rash were enrolled, unlike in ours.

Infants residing in urban areas were the most represented. Our results are contrary to those of Li et al in 2012 in China ${ }^{6}$ who noted that most of their patients were from the rural areas. This difference could be due to the study setting with respect to the residence of the mother. Patients will tend to go to the nearest hospital whatever the setting.

In our study, the most represented age group of the mothers was 20 to 29 years of age. This could be explained by the fact that it is within this age range that most women deliver, and most do not have experience in baby hygiene.

The infants of mothers living as couples were the most represented in our study population. These results are similar to those of Wanjiku et al in 2016 in Kenya. ${ }^{7}$ A possible explanation is that women living as part of a couple are more likely to have less time for the hygiene of the infants since they must also cater for the rest of the family.

Regular wearing of diapers was noted in all infants. For hygiene and body care of the infants, most of them used both types of diapers (disposable and reusable), followed by those using the disposables. Several mechanisms could explain the imputability of the nappies in the occurrence of diaper rash- if the diapers are not properly used, an occlusive effect may occur leading to an increase in skin hydration by inhibiting skin evaporation and transdermal water losses and skin $\mathrm{pH}^{9,10}$

Diapers, especially the disposable ones, can be irritative due to the poor fabrication quality of the napkins. Reusable diapers could also be irritative if they are of a plastic fabric. Studies conducted by Campbell et al and cited by Moulonguet-Michau, ${ }^{9}$ noted that disposable diapers were less irritating than reusable diapers.

Average frequency of diaper change was 5.76 times per day. In our study, infants whose frequency of diaper change was less than 6 times per day were the most affected. Our results are similar to those noted by Li et al in 2012 in China. ${ }^{6}$ Some authors have noted that an infant urinates 10 to 20 times a day and passes stool 3 to 4 times per day, ${ }^{11}$ suggesting that on several occasions, the infant had to urinate and stay with its diaper wet. Moulonguet-Michau et al noted that one of the factors which determines the appearance of diaper dermatitis is the time of contact of the skin with the irritating factor. ${ }^{9}$ Diaper change must therefore be done immediately after each episode of passing urine.

Few mothers clean the buttocks of their infants after they had passed urine, not knowing that urine and stools play a very important role in the occurrence of diaper rash. Indeed, the mixture of stools and urine in the diaper will cause a transformation (induced by the bacteria present in the stool) of urea into ammonia, which will increase the $\mathrm{pH}$ of the skin in this area. This rise in $\mathrm{pH}$ causes a reactivation of the digestive enzymes, which irritate the baby's skin and increases permeability of the skin., ${ }^{42}$

The most frequently used body oil was palm kernel oil ( $72.7 \%$ of cases). This could be due to the fact that this product is locally available and is most often recommended by health personnel in our health facilities for its hypoallergenic properties; nevertheless, the frequency of diaper rash was high in infants using this oil, although the reason for this finding still remains unclear.

The "W" type dermatitis or chaffing dermatitis was the most frequently encountered dermatitis in $48.1 \%$ of our patients. According to Moraillonl ${ }^{11}$ and Piérard-Franchimont, ${ }^{13}$ the most frequent diaper rash lesions have the "W" topography or frictional dermatitis, due to mechanical reaction in which occlusion and maceration play a key role. Diaper dermatitis complicated with the presence of C. albicans presents a beefy, red, raised-edge skin rash with pinpoint satellite lesions, which often extend into the folds of the skin in the diaper area. Whenever diaper dermatitis fails to respond to treatment, Candida diaper dermatitis should be considered as an alternate cause of the presenting rash. Because $C$. albicans is contained in the lower intestine of infants, fecal matter presents the primary source for Candida diaper dermatitis. In some instances, in addition to Candida diaper dermatitis, oral dermatitis (thrush) may be present, and the infant may require treatment with an oral antifungal agent. ${ }^{14}$

Therefore, healthcare personnel should inform, educate, and communicate with mothers on hygiene and body care of 
their babies to avoid this disorder that can lead to discomfort and reduced well-being of the infant.

\section{Conflict of Interest}

None.

\section{References}

1 Stevenson J. Getting to the bottom of nappy rash. Nurse Prescribing. 2011;9(01):25-27

2 Philipp R, Hughes A, Golding J; ALSPAC Survey Team. Avon Longitudinal Study of Pregnancy and Childhood. Getting to the bottom of nappy rash. Br J Gen Pract 1997;47(421):493-497

3 Ravanfar P, Wallace JS, Pace NC. Diaper dermatitis: a review and update. Curr Opin Pediatr 2012;24(04):472-479

4 Stamatas GN, Tierney NK. Diaper dermatitis: etiology, manifestations, prevention, and management. Pediatr Dermatol 2014;31 (01):1-7

5 Lagier L, Mazereeuw-Hautier J, Raffin D, Beneton N, Lorette G, Maruani A; Société française de dermatologie pédiatrique. Diaper dermatitis [article in French]. Ann Dermatol Venereol 2015;142 (01):54-61; quiz 53, 62
6 Li CH, Zhu ZH, Dai YH. Diaper dermatitis: a survey of risk factors for children aged 1-24 months in China. J Int Med Res 2012;40 (05):1752-1760

7 Wanjiku A, Ng“ang“a Z, Mbakaya C, Habtu M. Socio-demographic and economic determinants of diaper dermatitis among children aged 0-24 months at Mbaghati District Hospital, Kenya: a cross sectional study. Int J Health Sci Res. 2016;6:239-247

8 Biranjia-Hurdoyal S, Pandamikum L. A study to investigate the prevalence of nappy rash among babies aged 0 to 36 months old in a tropical country. Aust J Dermatol 2015;2(02):1040

9 Moulonguet-Michau. Dubertret. Le Manuel du Resident - Pédiatrie II. Dermatite de siège. Édition Tsunami. 2009:3455-3465

10 Longhi F, Carlucci G, Bellucci R, di Girolamo R, Palumbo G, Amerio P. Diaper dermatitis: a study of contributing factors. Contact Dermat 1992;26(04):248-252

11 Moraillon I. L'érythème fessier du nourrisson en pratique quotidienne. Dermatologie Pratique. 1994;138:1-2

12 Beguin A. L'érythème fessier: toujours d'actualité? Arch Pediatr 2006;13:6-9

13 Piérard-Franchimont GE. La dermatite des langes. Revue Dermatologie Tropicale; 1993:605

14 Merrill L. Prevention, treatment and parent education for diaper dermatitis. Nurs Womens Health 2015;19(04):324-336, quiz 337 